\title{
UPOTREBA FJUČERSA ZA HEDŽOVANJE RIZIKA NA TRŽIŠTU ELEKTRIČNE ENERGIJE
}

\author{
Tatjana Latas ${ }^{1, *}$, \\ Zoran Jeremić2 \\ ${ }^{1}$ Somborelektro d.0.0., \\ Sombor, Srbija \\ 2Univerzitet Singidunum, \\ Beograd, Srbija
}

Odgovorno lice:

Tatjana Latas

e-pošta:

tatjana.latas@somborelektro.rs
Rezime:

Na kretanje cena električne energije na tržištu utiče veliki broj faktora, te je veoma složeno predviđati kretanje tržišnih cena na kratak, a pogotovo duži rok i doneti odluku kada i u kojoj količini nabaviti ili prodati električnu energiju. Predviđanje kretanja cena električne energije stoga predstavlja veliki izazov, jer nosi visoke rizike, što direktno može da utiče na poslovanje kompanija. Ovi rizici se mogu ublažiti primenom adekvatnih hedžing strategija, pa u ovom radu istražujemo mogućnosti smanjenja rizika upotrebom fjučersa na električnu energiju. Ova tema dobija na aktuelnosti i značaju budući da EEX u saradnji sa SEEPEX uvodi fjučerse za srpsko tržište.

Ključne reči:

hedžing, fjučers, EEX, SEEPEX.

\section{UVOD}

Izlažući se nekontrolisanom riziku od stalnih promena spot cena električne energije, učesnici na tržištu električne energije su često u situaciji da kreiraju gubitke. Kontrolisati i smanjiti tržišne rizike je moguće primenom adekvatnog hedžinga (engl. hedging). U većini slučajeva hedžing tehnike, podrazumevaju upotrebu finansijskih derivata, čija je suštinska uloga da smanje tržišne rizike, te ih učesnici tržišta električne energije sve više koriste.

Razlozi za hedžovanje rizika na tržištu električne enegije mogu biti raznovrsni. Zbog izrazite volatilnosti cena električne energije, cenovni rizik pretstavlja posebnu pretnju za uspeh kompanija, koji se može ublažiti upotrebom robnih derivata za hedžiranje. Upotrebom robnih derivata za hedžiranje korisnici mogu imati višestruke koristi: izbegavanje nepovoljnih cenovnih kretanja, osiguranje sigurne prodaje/nabavke, sigurni dugoročni novčani tokovi [1]

$\mathrm{Na}$ tržištu derivata za električnu energiju, za razliku od spot tržišta, ugovaraju se isporuke za duži vremenski period, cene odražavaju buduća očekivanja spot cena, pa su ova tržišta daleko veća po obimu trgovanja, sa relativno niskom volatilnošću. 
Cene na tržištu derivata se formiraju pod uticajem mnogobrojnih faktora: spot cena (vreme, raspoloživost, sezona, doba dana, operativni troškovi, strani ponuđači) ekonomski rast, situacija na drugim tržištima, posebni događaji (moratorijum na elektrane), politička situacija.

Učesnici tržišta električne energije poput proizvođača, dobavljača, snabdevača, te ostalih učesnika sposobnih za upravljanje rizicima, koriste se različitim finansijskim instrumentima da se zaštite od rizika promena cena: terminskim ugovorima (fjučers i forvard), ugovorima o zameni jedne vrste imovine za drugu (svopovi) i opcijama.

Jedan od najšire primenjenih derivata na tržištu električne energije su fjučersi, koji mogu da budu sklopljeni na berzi ili izvan berze. Učesnici tržišta električne energije najčešće koriste fuučers ugovore da bi se zaštitili od gubitaka zbog stalnih promena spot cena na tržištu električne energije. Da bi se postigao cilj, odnosno da bi se zaštitili od rizika, mora im prethoditi uspešno savladavanje tehnike njihovog korištenja, kao i pravilna primena hedžing metode. U ovom radu dat je paralelan prikaz primene jednostavne i metode dinamičkog hedžiranja fjučers ugovora.

Kupoprodaja električne energije se odvija na berzi ili izvan berze. Na berzama je, zbog strogih pravila zagarantovana likvidnost trgovanja, odnosno tržišni učesnici mogu izvoditi fjučers ugovore samo pod uslovom da otvore račun na kojem će polagati novac, garancije ili hartije od vrednosti za pokrivanje margina u slučaju kad terminske cene električne energije rastu u odnosu na fiksno utvrđenu cenu. U suprotnom, učesnik tržišta na tom računu sakuplja kredite koje će iskoristiti u trenucima ponovnog rasta terminskih cena. Upravo taj mehanizam trgovanja čini berzu likvidnom.

Prilikom sklapanja fjučers ugovora utvrđuje se: ukupna količina električne energije koja treba biti isporučena, cena, mesto isporuke, trajanje isporuke, količina električne energije tokom razdoblja isporuke, te poslednji dan za trgovanje koji pada na datum konačnog ispunjavanja obaveza prema fučers ugovoru.

Fjučers ugovori imaju minimalni rok dospeća od sat vremena do najviše jedne godine. Fjučers ugovori mogu biti sa fizičkim i finansijskim poravnanjem. Uobičajena je praksa da su ugovori o fizičkoj isporuci električne energije ugovori koji dospevaju u roku jednog sata ili jednog dana, a da ugovori koji dospevaju u roku nedelju ili mesec dana mogu biti i fizički i finansijski, te da se njima trguje putem brokera ili ih učesnici tržišta direktno izvode na tržištima izvan berze.

\section{PRIMENA HEDŽING METODA NA FJUČERS UGOVORE}

Primenjivati hedžing znači zaštiti se ili osigurati od negativnih pojava, koje se ne moraju dogoditi, ali i ako se dogode dobar hedžing će ih značajno ublažiti. Stoga je primena hedžinga prisutna gotovo svugde i gotovo svakodnevno. Investitori i upravljači portfeljima najčešće koriste hedžing kako bi bili što manje izloženi raznoraznim rizicima. Investitori štite jednu investiciju time što stvaraju drugu investiciju. Hedžiranje podrazumeva istovremeno dve investicije u kojima jedna investicija pokriva ili štiti drugu. Smanjenje rizika uvek podrazumeva i smanjenje potencijalne dobiti, što znači da se hedžiranjem ne stvaraju viškovi dobiti, već se smanjuje potencijalni gubitak. Ako neka investicija koja je hedžirana stvara dobit, onda će dobit od te investicije biti manja nego od investicije koja nije hedžirana i obrnuto, ako investicija koja je hedžirana rezultira gubitkom, tada će taj gubitak, zahvaljujući hedžiranju, biti smanjen ili izbegnut. Imajući u vidu visoku volatilnost cena električne energije, hedžing metode nalaze svoju punu primenu na tržištima električne energije.

Za primenu hedžing metode osnovno je da se utvrdi razlika između spot cene i terminske cene električne energije. Pretpostavka je da se zarada ostvaruje kada vrednosti tih cena konvergiraju. Kao jednostavan primer može se uzeti ugovor sklopljen između prodavaca i kupca na berzi, s unapred određenom cenom električne energije od $50 \mathrm{EUR} / \mathrm{MWh}$, za ugovorenu količinu električne energije od $100 \mathrm{MWh}$. Zadata transakcija će se obaviti preko berze. Ako je u trenutku ispunjenja ugovornih obaveza cena na berzi $60 \mathrm{EUR} / \mathrm{MWh}$, tada će prodavac dobiti $60 \mathrm{EUR} / \mathrm{MWh}$, ali će razliku od 10 EUR/MWh vratiti kupcu. I obrnuto, kupac će platiti razliku prodavacu ako se dogodi da je u trenutku isporuke cena električne energije na berzi manja od ugovorene. To rezultira anuliranjem dobiti jer obe ugovorne strane, tj. kupac i prodavac, plaćaju električnu energiju po ugovorenoj ceni. Vidljivo je da ugovorna strana koja plaća razliku u ceni električne energije nije iskoristila mogućnost za većom dobiti koju bi ostvarila prema tržišnoj ceni s berze, pošto je prethodno hedžirala svoju poziciju od tržišnog rizika.

\section{Vrednost fučers ugovora sa fiksnom cenom}

Smisao fjučers ugovora je taj da se odredi njegova vrednost u svakom trenutku $t$ do trenutka $T$ kada on 
ističe, a u odnosu na kupoprodaju električne energije po fiksno utvrđenoj ceni $X$ po jedinici električne energije. Pretpostavlja se da vrednost fjučers ugovora sve više raste, odnosno sve više pada što se više približava trenutak njegovog isteka. Iz toga proizlazi da je vrednost fjučers ugovora za onu stranu koja plaća električnu energiju po fiksno utvrđenoj ceni $X$ jednaka [2]:

$\mathrm{V}\left(\mathrm{t}, \mathrm{F}_{\mathrm{tT}}\right)=\mathrm{e}^{-\mathrm{r}(\mathrm{T}-\mathrm{t})}\left(\mathrm{F}_{\mathrm{tT}}-\mathrm{X}\right)$

gde je: $r$ - bezrizična kamata, a $F_{t, T}$ - cena električne energije u trenutku $t$ utvrđena prema fjučers ugovoru. Za stranu koja isporučuje električnu energiju vrednost fjučers ugovora izračunava se na sledeći način:

$V\left(t, F_{t T}\right)=e^{-r(T-t)}\left(X-F_{t T}\right)$

Prethodni izrazi dobijeni su na osnovu pretpostavljenog izjednačavanja vrednosti terminske i spot cene u trenutku isteka fjučers ugovora (pretpostavka konvergencije):

$\mathrm{F}_{\mathrm{T}, \mathrm{T}}=\mathrm{S}_{\mathrm{T}}$

Za dokazivanje ove pretpostavke koristi se metoda dinamičkog hedžiranja (delta hedžing) u određenim trenucima $t 0, t 1, t 2, \ldots, t \mathrm{n}=T$. Uspešni delta hedžing proizlazi iz sledeće jednačine [2]:

$\left.\mathrm{V}\left(\mathrm{T}, \mathrm{F}_{\mathrm{TT}}\right)+\mathrm{e}^{\mathrm{r}(\mathrm{T}-\mathrm{t})} \delta_{0} \Delta \mathrm{F}_{0}+\mathrm{e}^{\mathrm{r}(\mathrm{T}-\mathrm{t})}{ }_{2} \delta_{1} \Delta \mathrm{F}_{1}+\ldots+\mathrm{e}_{\mathrm{i}+1}^{\mathrm{r}(\mathrm{T}-\mathrm{t}}\right)$ $\delta_{\mathrm{i}} \Delta \mathrm{F}_{\mathrm{i} . \ldots+} \delta_{\mathrm{n}-\mathrm{1}} \Delta \mathrm{F}_{\mathrm{n}-\mathrm{1}}=\mathrm{e}^{\mathrm{r}(\mathrm{T}-\mathrm{t})} \mathrm{V}\left(\mathrm{t}_{0}, \mathrm{~F}_{\mathrm{t} 0, \mathrm{~T}}\right)$

gde su:

$\delta_{1}=\partial \mathrm{V} / \partial \mathrm{F}\left(\mathrm{T}_{\mathrm{i}} \mathrm{F}_{\mathrm{ti}} \mathrm{T}\right) \mathrm{i} \Delta \mathrm{Fi}=\mathrm{F}_{\mathrm{tit}+1, \mathrm{~T}}-\mathrm{F}_{\mathrm{ti}, \mathrm{T}}$

uvrštavajući u prethodne izraze pretpostavku konvergencije dobijamo:

$\left(\mathrm{S}_{\mathrm{T}}-\mathrm{X}\right)+\mathrm{e}_{1}^{\mathrm{r}(\mathrm{T}-\mathrm{t})} \delta_{0} \Delta \mathrm{F}_{0}+\ldots+\delta_{\mathrm{n}-1} \Delta \mathrm{F}_{\mathrm{n}-1}=\left(\mathrm{F}_{\mathrm{t} 0^{3} \mathrm{~T}}-\mathrm{X}\right)$

koji se odnosi na kupca (primaoca) električne energije,

$\left.\left(\mathrm{X}-\mathrm{S}_{\mathrm{T}}\right)+\mathrm{e}^{\mathrm{r}(\mathrm{T}-\mathrm{t}}{ }_{1}\right) \delta_{0} \Delta \mathrm{F}_{0}+\ldots+\delta_{\mathrm{n}-1} \Delta \mathrm{F}_{\mathrm{n}-1}=\left(\mathrm{X}-\mathrm{F}_{\mathrm{t} 0, \mathrm{~T}}\right)$ koji se odnosi na prodavaca (isporučioca) električne energije.

Značenje izraza i parametara je sledeće: $X$ - fiksno utvrđena cena električne energije, $S_{T}$ - spot cena električne energije, $\mathrm{e}^{r(T-t)} \delta_{0} \Delta F_{0}+\ldots+\delta_{\mathrm{n}-1} \Delta F_{\mathrm{n}-1}-$ obračun margina (marginski račun), $F_{t 0^{3} T}$ - cena električne energije $\mathrm{u}$ trenutku $t_{0}$ prema fjučers ugovoru.

Izrazi pokazuju da je pravilno utvrđena cena električne energije u svakom trenutku valjanosti fjučers ugovora jednaka:

$\mathrm{X}=\mathrm{F}_{\mathrm{Tt}}$

Neto sadašnja vrednost ugovora pri ovoj ceni je jednaka nuli. Transparentnost cena jedna je od najvažnijih karakteristika koja čini tržište fjučers ugovora likvidnim. Sposobnost kvalitetne primene hedžing metode predstavlja glavni razlog zašto se obe ugovorne strane mogu i žele dogovoriti oko utvrđivanja cene električne energije po fjučers ugovoru.

Primena hedžing metode kod fučers ugovora može se prikazati sledećim primerom [2]. Snabdevač električnom energijom $u$ fazi pronalaženja načina kako da snabde svoje potrošače tokom letnjeg perioda, $s$ ciljem da ostvari što veće prihode, polazi od pretpostavke da bi spot cena električne energije u tom razdoblju mogla biti visoka i varijabilna. Da bi se zaštitio od mogućih gubitaka donosi odluku da što je pre moguće utvrdi cenu za taj period u godini, na primer 1 . januara. Snabdevač pregovara s dobavljačem električne energije oko utvrđivanja cene električne energije za isporuku u julu posmatrane godine. Na dan 1. januara (datum označen sa $t_{0}$ ) utvrđena cena električne energije je jednaka $X=50$ EUR/MWh. To znači da su se obe ugovorne strane (snabdevač i dobavljač) dogovorile oko toga da će u julu posmatrane godine dobavljač isporučiti ugovorenu količinu on-peak električne energije u iznosu od 73.600 MWh, koju će snabdevač platiti po fiksno utvrđenoj ceni od $X=50$ EUR/MWh. Na taj način se snabdevač zaštitio od promena spot cena tokom letnjeg perioda. Međutim, ovakav ugovor je dobavljača električne energije izložio riziku, pa je on odmah počeo primenjivati hedžing, koji će rezultirati različitim strategijama dinamičkog hedžiranja (tabela 1 i 2). Po pravilu on će odmah na terminskom tržištu zauzeti poziciju koja je po veličini ista, a po smeru suporotna od pozicije koju drži na spot tržištu. 
Tabela 1. Strategija dinamičkog hedžiranja kod rasta terminskih cena

\begin{tabular}{|c|c|c|c|c|c|c|c|c|}
\hline $\begin{array}{c}\text { korak } \\
\text { hedžiranja }\end{array}$ & Datum & $\begin{array}{c}\text { Terminska } \\
\text { cena EUR/ } \\
\text { MWh }\end{array}$ & $\begin{array}{l}\text { Vrednost } \\
\text { ugovora } \\
\text { (EUR) }\end{array}$ & $\begin{array}{c}\text { Razlika u } \\
\text { vrednosti } \\
\text { ugovora } \\
\text { (EUR) }\end{array}$ & $\begin{array}{c}\text { Delta } \\
\text { hedžing } \\
(\mathrm{MWh})\end{array}$ & $\begin{array}{c}\text { Broj } \\
\text { ugovora }\end{array}$ & $\begin{array}{l}\text { Račun } \\
\text { margina } \\
\text { (EUR) }\end{array}$ & $\begin{array}{c}\text { Razlika } \\
\text { u računu } \\
\text { margina } \\
\text { (EUR) }\end{array}$ \\
\hline 1 & 1.jan & 50 & 0 & & $71.501,15$ & 97 & 0 & \\
\hline 2 & 1.feb & 55 & $-359.332,20$ & $-359.332,20$ & $71.866,44$ & 98 & $358.783,67$ & $358.783,67$ \\
\hline 3 & 1.mar & 60 & $-721.979,86$ & $-362.647,65$ & $72.197,99$ & 98 & $722.742,62$ & $363.958,95$ \\
\hline 4 & 1.apr & 70 & $-1.451 .336,76$ & $-729.356,90$ & $72.566,84$ & 99 & $1.451 .399,99$ & $728.657,37$ \\
\hline 5 & 1.maj & 80 & $-2.187 .767,57$ & $-736.430,81$ & $72.925,59$ & 99 & $2.190 .817,42$ & $739.417,43$ \\
\hline 6 & 1.jun & 90 & $-2.931 .926,20$ & $-744.158,63$ & $73.298,15$ & 100 & $2.934 .372,63$ & $743.555,21$ \\
\hline $\begin{array}{c}\text { Istek } \\
\text { ugovora }\end{array}$ & 26.jun & 100 & $-3.680 .000,00$ & $-748.073,80$ & & & $3.685 .487,39$ & $751.114,76$ \\
\hline
\end{tabular}

Izvor: Eydeland, A., Volyniec, K., Energy Power and Risk Menagement

Tabela 2. Strategija dinamičkog hedžiranja kod padaterminskih cena

\begin{tabular}{|c|c|c|c|c|c|c|c|c|}
\hline $\begin{array}{c}\text { korak } \\
\text { hedžiranja }\end{array}$ & Datum & $\begin{array}{c}\text { Terminska } \\
\text { cena EUR/ } \\
\text { MWh }\end{array}$ & $\begin{array}{l}\text { Vrednost } \\
\text { ugovora } \\
\text { (EUR) }\end{array}$ & $\begin{array}{l}\text { Razlika u } \\
\text { vrednosti } \\
\text { ugovora } \\
\text { (EUR) }\end{array}$ & $\begin{array}{c}\text { Delta } \\
\text { hedžing } \\
(\mathrm{MWh})\end{array}$ & $\begin{array}{c}\text { Broj } \\
\text { ugovora }\end{array}$ & $\begin{array}{l}\text { Račun } \\
\text { margina } \\
\text { (EUR) }\end{array}$ & $\begin{array}{l}\text { Razlika } \\
\text { u računu } \\
\text { margina } \\
\text { (EUR) }\end{array}$ \\
\hline 1 & 1.jan & 50 & 0 & & $71.501,15$ & 97 & 0 & \\
\hline 2 & 1.feb & 47 & $215.599,32$ & $215.599,32$ & $71.866,44$ & 98 & $-215.270,20$ & $-215.270,20$ \\
\hline 3 & 1.mar & 43 & $505.385,90$ & $289.786,58$ & $72.197,99$ & 98 & $-506.106,33$ & $-290.836,13$ \\
\hline 4 & 1.apr & 40 & $725.668,38$ & $220.282,48$ & $72.566,84$ & 99 & $-726.181,45$ & $-220.075,12$ \\
\hline 5 & 1.maj & 35 & $1.093 .883,78$ & $368.215,41$ & $72.925,59$ & 99 & $-1.095 .892,55$ & $-369.711,10$ \\
\hline 6 & 1.jun & 33 & $1.246 .068,63$ & $152.184,85$ & $73.298,15$ & 100 & $-1.247 .963,86$ & $-152.071,31$ \\
\hline $\begin{array}{l}\text { Istek ugo- } \\
\text { vora }\end{array}$ & 26.jun & 27 & $1.692 .800,00$ & $446.731,37$ & & & $-1.696 .521,56$ & $-448.557,70$ \\
\hline
\end{tabular}

Izvor: Eydeland, A., Volyniec, K., Energy Power and Risk Menagement

Tabele 1 i 2 prikazuju strategiju dinamičkog hedžiranja snabdevača, gde je fučers ugovor valjan i to u oba scenarija, kad terminske cene električne energije rastu i kad padaju.

Način računanja vrednosti iz tabele 1 je sledeći:

Vrednost ugovora u 2. koraku hedžiranja:

$\mathrm{V}\left(\mathrm{t}, \mathrm{F}_{\mathrm{tT}}\right)=\mathrm{e}^{-\mathrm{r}(\mathrm{T}-\mathrm{t})}\left(\mathrm{X}-\mathrm{F}_{\mathrm{tT}}\right)=\mathrm{e}^{-0,06((176-31) / 365)} \cdot(50-55) \cdot 73.600=$ $-359.332,20$ EUR

gde je $6 \%$ bezrizična kamata, broj dana između 01.01. i 26.06. je 176, umanjen za 31 dan, što je jednako broju dana između 1. i 2. koraka hedžiranja.

Delta hedžing:

$\delta_{2}=\mathrm{e}^{-\mathrm{r}(\mathrm{T}-\mathrm{t})} \cdot 73.600=\mathrm{e}^{-0,06((176-31) / 365)} \cdot 73.600=71.866,44$ MWh
Broj ugovora:

$\mathrm{n}=\mathrm{e}^{-\mathrm{r}(\mathrm{T}-\mathrm{t})} \cdot=\mathrm{e}^{-0,06((176-31) / 365)}=0,976^{\star} 100=98$

Obračun margina:

$\mathrm{e}^{0,06(31 / 365)} \cdot 0,97 \cdot(55-50) \cdot 73.600=358.783,67$ EUR

$\mathrm{Na}$ isti način se računaju vrednosti iz tabele 2 . Na štetu dobavljača idu terminske cene kojima vrednosti rastu pa će se na kraju juna posmatrane godine on suočiti s gubitkom u iznosu od 3.680.000 eura (u slučaju da spot cena u trenutku isteka fjučers ugovora iznosi 100 EUR/ MWh), jer se obavezao snabdevaču isporučiti električnu energiju po fiksno utvrđenoj ceni od 50 EUR/MWh. Međutim, novac koji je dobavljač položio na svom marginskom računu poništiće taj gubitak. U slučaju kad 
terminske cene padaju (tabela 2), dobavljač će zaraditi na isporuci električne energije, te vratiti dug koji je stvorio na marginskom računu. Odnosno, dobavljač će u trenutku isteka fjučers ugovora kupiti električnu energiju po spot ceni od 27 EUR/MWh i isporučiti je snabdevaču po fiksno utvrđenoj ceni od 50 EUR/MWh.

Ako pretpostavimo da je, umesto dinamičnog hedžinga, snabdevač izabrao drugačiju strategiju kako bi se zaštitio od rizika, te da je na početku ugovora kupio fjučerse za punu količinu električne energije koju je bio dužan isporučiti kupcu, u tom slučaju, to bi bilo 73.600 MWh ili 100 fjučers ugovora po ceni od 50 EUR/MWh. Čini se da se dobro zaštio, budući da će po dospeću snabdevač preuzeti isporuku za svoju dugu poziciju fjučersa od 73,600 MVh plaćajući 50 EUR/MWh, a zatim isporučiti električnu energiju kupcu, primajući $50 \mathrm{EUR} /$ MWh. U stvarnosti, ova statička hedžing strategija ima neke rizike kao što je prikazano u Tabeli 3 , gde je strategija primenjena na scenario 2 iz tabele 2 .

Tabela 3. Statična hedžing metoda primenjenja na scenario 2

\begin{tabular}{|c|c|c|c|c|c|c|c|c|}
\hline $\begin{array}{c}\text { korak } \\
\text { hedžiranja }\end{array}$ & Datum & $\begin{array}{c}\text { Terminska } \\
\text { cena EUR/ } \\
\text { MWh }\end{array}$ & $\begin{array}{l}\text { Vrednost } \\
\text { ugovora } \\
\text { (EUR) }\end{array}$ & $\begin{array}{c}\text { Razlika u } \\
\text { vrednosti } \\
\text { ugovora } \\
\text { (EUR) }\end{array}$ & $\begin{array}{c}\text { Delta } \\
\text { hedžing } \\
(\mathrm{MWh})\end{array}$ & $\begin{array}{c}\text { Broj } \\
\text { ugovora }\end{array}$ & $\begin{array}{c}\text { Račun } \\
\text { margina } \\
\text { (EUR) }\end{array}$ & $\begin{array}{l}\text { Razlika } \\
\text { u računu } \\
\text { margina } \\
\text { (EUR) }\end{array}$ \\
\hline 1 & 1.jan & 50 & 0 & & $71.501,15$ & 100 & & \\
\hline 2 & 1.feb & 47 & $215.599,32$ & $215.599,32$ & $71.866,44$ & 100 & $221.928,04$ & $221.928,04$ \\
\hline 3 & 1.mar & 43 & $505.385,90$ & $289.786,58$ & $72.197,99$ & 100 & $518.710,05$ & $296.782,01$ \\
\hline 4 & 1.apr & 40 & $725.668,38$ & $220.282,48$ & $72.566,84$ & 100 & $743.288,13$ & $224.578,08$ \\
\hline 5 & 1.maj & 35 & $1.093 .883,78$ & $368.215,41$ & $72.925,59$ & 100 & $1.116 .781,99$ & $373.493,86$ \\
\hline 6 & 1.jun & 33 & $1.246 .068,63$ & $152.184,85$ & $73.298,15$ & 100 & $1.270 .439,54$ & $153.657,55$ \\
\hline $\begin{array}{c}\text { Istek } \\
\text { ugovora }\end{array}$ & 26.jun & 27 & $1.692 .800,00$ & $446.731,37$ & & & $1.719 .089,80$ & $448.650,26$ \\
\hline
\end{tabular}

Izvor: Eydeland, A., Volyniec, K., Energy Power and Risk Menagement

Iz tabele se nedvosmisleno može utvrditi da će snabdevač primenjujući ovu strategiju imati deficit od 23,698.57 EUR na isteku ročnosti fjučersa i da neće biti u mogućnosti da pokrije marginu. Razlika koja se pojavila na marginskom računu je akumulirana kamata.

Na početku, vrednost posla je nula. Savršena hedžing strategija samo će sačuvati nultu vrednost pod tržišnim kretanjima. Prema tome, ako snabdevač odluči da se zaštiti, jedini način da se zaštiti je primenom adekvatne hedžing metode.

\section{PRIMENA FJUČERS UGOVORA NA EEX}

Fjučers ugovor je tipičan za berzu EEX. Osnov za uspostavljanje fjučers ugovora na EEX je isporuka ili prihvatanje isporuke električne energije sa stalnom snagom od $1 \mathrm{MW}$ u maksimalnom naponskom nivou definisanog tržišta u toku vremena isporuke za svaki dan isporuke u periodu isporuke [3]. Na EEX berzi, članovi berze, obavljaju kupovinu / prodaju električne energije tako da odrede cenu u EUR/MWh kao i broj fjučers ugovora kojim žele trgovati. U zavisnosti od porudžbine i faze trgovanja, porudžbine se beleže u knjizi porudžbina. Na EEX-u je moguće trgovati dnevnim, vikend, nedeljnim, mesečnim, kvartalnim, sezonskim (zimska sezona oktobar - mart ili letnja sezona april - septembar) i godišnjim fučersima. Prema vremenu isporuke (satu u toku dana) fjučersi mogu biti kreirani za bazni, vršni i period van vršnog opeterećenja, što je navedeno u samom imenu fjučersa tako da se Base odnosi na bazno opterećenje elektroenergetskog sistema (00-24h svakog dana), Peak na vršno opterećenje EES-a (08-20 svakog dana - radni dan / vikend), a Off-Peak na periode van vršnog opterećenja (00-08 i 20-24 od ponedeljka do petka i 00-24 vikendom). Obim ugovora se računa množenjem broja sati isporuke, tokom perioda isporuke (h) sa konstantnim outputom (MW) navedenim u odgovarajućem ugovoru [3]. Na EEX-u je moguće ugovoriti fjučerse samo sa finansijskim poravnanjem u odnosu na spot cenu za hedžovanu električnu energiju, 
gde kupac/prodavac prima razliku između cene fjučersa i spot cene na tržištu kao finansijsku nadoknadu.

Berza EEX zahteva da se odmah nakon zaključenja ugovora, kod klirinše kuće ECC položi sigurnosni depozit kako bi smanjio mogući rizik neizmirenja obaveza. Taj sigurnosni depozit naziva se inicijalna margina $\mathrm{i}$ utvrđuje se od strane ECC-a na osnovu veličine ugovora i parametara volatilnosti za ugovor. Inicijalne margine se vraćaju ugovornim stranama, nakon dospelosti fučers ugovora [1]. Ove margine se računaju u EUR/MWh. Na primer, neka je parametar inicijalnih margina za ugovor tipa Phelix Base Month Futures jednak 2 EUR/MWh, to znači da će u slučaju ugovorene količine električne energije od $720 \mathrm{MWh}$, ukupne inicijalne margine iznositi: 2 EUR/MWh x $720 \mathrm{MWh}=1.440 \mathrm{EUR}$.

EEX Power Future ugovori su dizajnirani da služe kao savršeno osiguranje za spot tržište na koje se odnose. Uzimajući aktuelne cene na spot tržištu za fizičku isporuku kao osnovu za finalnu cenu poravnanja, osnovni rizik se izbegava pošto se plaćanja balansiraju između ugovornih strana [4].

Izvođenje fjučers ugovora rezultira utvrđivanjem dnevne dobiti i gubitka. Promene u vrednosti fjučers ugovora utvrđuju se svakodnevno nakon čega sledi formiranje nove cene poravnanja koja je odraz trenutne spot cene na tržištu. Za podmirivanje fjučers pozicija zbog promene dnevnih cena poravnanja koriste se varijacijske margine. Varijacijske margine se računaju na osnovu cena poravnanja, koje se računaju različito za period pre meseca isporuke i za mesec isporuke. $\mathrm{Za}$ određivanje cena poravnanja tzv. teoretska cena poravnanja do početka meseca isporuke je presudna knjiga porudžbina (metod zavisi od broja validnih trgovina i porudžbina koje zadovoljavaju posebne zahteve u vezi sa predmetom trgovanja, odnosno izvori informacija za ustanovljenje cena su trgovine, narudžbe, postupak glavnog trgovca (fer vrednosti) i druge informacije), dok je za određivanje cena u toku meseca isporuke, za ustanovljavanje cene poravnanja relevantna spot cena (npr. konačna cena poravnanja za mesečni fjučers se utvrđuje kao srednja vrednost spot tržišnog indeksa za odgovarajući mesec) na odgovarajućem tržištu [5]. Na taj način se eliminiše bazni rizik (bazni rizik se povećava kada raste vremenska razlika između isteka hedža i meseca dospeća [6].

Varijacijske margine računaju se na sledeći način: broj ugovora $\mathrm{x}$ ugovorena količina električne energije $\mathrm{x}$ (utvrđena cena na današnji dan trgovanja na berzi utvrđena cena na jučerašnji dan trgovanja na berzi). Pozitivni iznos ove formule znači dobit od preuzete fjučers pozicije, dok negativni iznos predstavlja gubitak zbog napuštanja te iste pozicije [7].
Varijacijska margina za fjučers poziciju, s kojom se ulazi na poslednji dan trgovanja na berzi, računa se na sledeći način: broj ugovora $\mathrm{x}$ ugovorena količina električne energije $\mathrm{x}$ (utvrđena cena na poslednji dan trgovanja na berzi - terminska cena). I u ovom slučaju pozitivni iznos znači dobit od preuzete pozicije, odnosno negativni iznos je gubitak zbog napuštanja te iste pozicije.

Na primer, snabdevač planira da kupi svakog sata 1 MW električne energije tokom novembra 2018. godine, što znači 30 dana, 24 sata, primenom satnih ugovora. Budući da se cena na spot tržištu ne može predvideti sa sigurnošću, snabdevač se odlučuje da se zaštiti od gubitaka na tržištu, na način da kupi 1 mesečni fjučers za novembar 2018. godine, po ceni od 30 EUR/MWh.Planirani budžet za nabavku električne energije iznosi: $1 \mathrm{MW}$ x 24 sata/dan x 30 dana x $30 \mathrm{EUR} / \mathrm{MWh}=21.600 \mathrm{EUR}$. Snabdevač je započeo s kupovinom električne energije 31. oktobra 2018. godine, što važi za prvi dan trgovanja (tj. 1. novembra), a završio 29. novembra 2018. godine i važi za poslednji dan trgovanja (odnosno 30. novembra). To znači da snabdevač svakih 24 sata daje ponudu po kojoj kupuje $1 \mathrm{MW}$ električne energije svakog sata po određenoj spot ceni. Prosečna cena koju snabdevač postigne trgovanjem na spot tržištu (tabela 5) jednaka je finalnoj ceni poravnanja za fjučers ugovor (tabela 4).

U tabeli 5 se može uočiti da cena poravnanja raste iznad planirane vrednosti od 30 EUR/MWh. Prema proseku, tržišni učesnik uspeva nabavati električnu energiju po ceni od 38,00 EUR/MWh na spot tržištu i zbog toga mu se planirani troškovi uvećavaju za 5.760,00 eura. Varijacijska margina pokriva nedostatak od 5.760,00 eura i dovodi do uravnoteženja računa dobiti i gubitka. To pokazuje da je planirani trošak od ukupno 21.600 eura već utvrđen transakcijom po fjučers ugovoru. Ukupan trošak se u tom smislu sastoji od cene ostvarene na spot tržištu: $720 \mathrm{MWh}$ x $38 \mathrm{EUR} / \mathrm{MWh}=27.360$, te prihoda ostvarenog na tržištu derivatima: $720 \mathrm{MWh} \times(30,00$ $\mathrm{EUR} / \mathrm{MWh}-38,00 \mathrm{EUR} / \mathrm{MWh})=-5.760,00 \mathrm{EUR}$.

Kao dodatnu meru obezbeđenja snabdevač je dužan, da nakon zaključenja fjučers ugovora, položi i inicijalnu marginu, koja se vraća po ugovornim stranama po završetku ugovornog perioda (u našem primeru, ako uzmemo da se inicijalna margina zasniva na parametru jednakom 2,00 EUR/MWh, snabdevač bi, preko svoje kliring kuće, morao u inicijalnu marginu položiti: $1 \mathrm{MW}$ x 24 sata/dan x 30 dana x 2,00 EUR/MWh = $1.440 \mathrm{EUR}$ od momenta preuzimanja fučers pozicije pa sve do 29 . novembra 2018. godine kad fjučers ugovor ističe i kada bi mu ta inicijalna margina, opet preko kliring kuće, bila vraćena). 
Tabela 4. Plaćanje na EEX na tržištu derivate (fjučers)

\begin{tabular}{|c|c|c|c|c|c|c|c|c|c|}
\hline & 31.10 . & 01.11. & 02.11 & 03.11 & $\ldots$ & 28.11 . & 29.11. & 30.11 & $\varnothing 38$ \\
\hline $\begin{array}{l}\text { dnevna spot cena } \\
\text { (EUR/MWh) }\end{array}$ & 34 & 34 & 38 & 38 & & 42 & 42 & & \\
\hline obim isporuke (MWh) & 24 & 24 & 24 & 24 & & 24 & 24 & & \\
\hline $\begin{array}{c}\text { kupovna cena na aukciji } \\
\text { EUR }\end{array}$ & -816 & -816 & -912 & -912 & & -1.008 & -1.008 & & -27.360 \\
\hline $\begin{array}{l}\text { varijacijska margina iz } \\
\text { fjučersa (EUR) }\end{array}$ & & & & & & & & & 5.760 \\
\hline rezultat EUR & & & & & & & & & 21.600 \\
\hline
\end{tabular}

Izvor: EEX, EEX/SEEPEX Cooperation

Tabela 5. Ispunjenje na tržišnoj spot aukciji

\begin{tabular}{|c|c|c|c|c|c|c|c|c|c|c|c|c|}
\hline & & & & & 01.11. & 02.11 & 03.11. & & 28.11. & 29.11. & 30.11 . & rezultat \\
\hline $\begin{array}{l}\text { cena ugovora } \\
\text { EUR/MWh }\end{array}$ & 30 & & & & & & & & & & & \\
\hline $\begin{array}{c}\text { konačna cena } \\
\text { poravnanja } \\
\text { EUR/MWh }\end{array}$ & 31 & 33 & 31 & 29 & 30 & 31 & 34 & $\ldots$ & 36 & & & \\
\hline $\begin{array}{l}\text { cena poravnan- } \\
\text { ja EUR/MWh }\end{array}$ & & & & & & & & & & 38 & & \\
\hline $\begin{array}{c}\text { promena EUR/ } \\
\text { MWh }\end{array}$ & +1 & +2 & -2 & -2 & +1 & +1 & +3 & & +2 & +2 & & +8 \\
\hline $\begin{array}{c}\text { obim ugovora } \\
\text { MWh }\end{array}$ & 720 & 720 & 720 & 720 & 720 & 720 & 720 & & 720 & 720 & & 720 \\
\hline pozicija & 1 & 1 & 1 & 1 & 1 & 1 & 1 & & 1 & 1 & & 1 \\
\hline $\begin{array}{c}\text { varijacijska } \\
\text { margina }\end{array}$ & +720 & +1.440 & -+1.440 & -+1.440 & +720 & +720 & +720 & & +1.440 & +1.440 & & +5.760 \\
\hline
\end{tabular}

Izvor: EEX, EEX/SEEPEX Cooperation

Ispunjenje na finansijskom tržištu je izvršeno slanjem cenovno nezavisne ponude koja prihvata sve cene. $\mathrm{Na}$ taj način, skoro da nema rizika ispunjenja. Nepovoljna cenovna kretanja su hedžovana putem fjučersa i obrnuto. Ovo zahvaljući tome, da je finalna cena poravnanja fučersa od 38 EUR prosek svih relevantnih dnevnih spot cena [1]. Naravno, postoje i suprotne situacije od situacije prikazane u tabeli 5 , a to je kad prosečna spot cena pada, pa u tom slučaju snabdevač električne energije može nabaviti jeftinije električnu energiju na spot tržištu, nego što je obezbedio fučers ugovorom. U svakom slučaju, cilj primene hedžing tehnike je zaštita od rizika sa kojim se susreću (ako izuzmemo spekulante na tržištu, koji koriste fjučerse za ostvarivanje profita).

SEEPEX i EEX su započeli saradnju za uvođenje fjučersa za električnu energiju sa finansijskim poravanjanjem za srpsko tržište. EEX će uvesti bazne mesečne, kvartalne i godišnje fjučerse za tržište Srbije. Finansijsko poravnanje će se vršiti u odnosu na spot cenu u Srbiji, koje objavljuje SEEPEX. Referentna cena i fizička isporuka biće obezbeđena preko SEEPEX infrastrukture ETS platforme i ECC kliringa [7].

Uvođenje fjučersa električne energije za srpsko tržište na EEX će doprineti daljem razvoju srpskog spot 
tržišta električne energije koje se brzo razvija, ali će omogućiti i primenu hedžinga na srpskom tržištu električne energije, gde će svi učesnici na tržištu imati koristi od standardizovanog proizvoda i mogućnost da se zaštite od cenovnih rizika na srpskom tržištu električne energije.

\section{ZAKLJUČAK}

Upravljanje tržišnim rizicima u trgovanju električnom energijom zahteva primenu adekvatnog hedžinga. Hedžing je kreiran da minimizira izlaganje nepoželjnom poslovnom riziku. Izbor pogrešne strategije hedžiranja može imati negativne posledice umesto pozitivnih.

Kvalitetno predviđanje budućih kretanja cena na bazi tekućih cena i svih faktora rizika koji postoje kod trgovanja električnom energijom, kao i odabir adekvatne hedžing strategije, osnova su uspešne zaštite od tržišnih rzika

S obzirom na činjenicu da se u Srbiji u vrlo bliskoj budućnosti otvara mogućnost hedžovanja cene električne energije, neophodno je intenzivirati sve oblike edukacije o zaštiti od tržišnih rizika, kako zaposlenih u energetskom sektoru, tako i njihovih korisnika (npr. veliki industrijski potrošači)

Daljim razvojem berzanskog trgovanja i uvođenjem fjučersa za srpsko tržiše doći će do povezivanja regionalnih berzi i njihove integracije u evropske berze na kojima je razvijeno trgovanje derivatima, usled čega postoji potreba širenja znanja i istraživanja u Srbiji vezanih za oblast trgovanja derivatima na električnu energiju.

\section{LITERATURA}

[1] EEX, EEX / SEEPEX Cooperation: Developing a long-term market for Serbian Power, Belgrade 09/18/2018,

[2] A. Eydeland, and K. Wolyniec, Energy and Power: Risk Management. New Jersey, John Wiley \& Sons, 2003., str. 20-29

[3] EEX, Contract specifications, Release 0066a, Leipzig, 21.03.2019., preuzeto sa: https://www.eex. com/blob/95388/14e077d08df371095f9f69ddd6ec 77a0/20190321-eex-contract-spezifications-0066ae-final-data.pdf

[4] D. Stojčevski, Tržište električne energije jugoistočne Evrope - aktuelnosti i inicijative, Regionalni energetski forum, Tuzla, 22.11.2018., preuzeto sa: http:// www.nerda.ba/pdf/REF18_2_SESIJA_Trziste_el_ energije_u_JI_Evropi_Dejan_Stojcevski.pdf

[5] EEX; EEX Settlement Pricing Procedure, Version 5.04., Leipzig, 29.10.2018., preuzeto sa: https://www. eex.com/blob/61950/6868332159cb71d90850ba2ab $45 \mathrm{ffdea} /$ settlement-pricing-procedure-data.pdf

[6] J.Hull, Options, Futures and Other Derivates 10th ed., New York, Pearson Education, 2018. str. 54-61

[7] S. Wilkens, and J. Wimschulte, The Pricing of Electricity Futures: Evidence from the European Energy Exchange. s.l, The Journal of Futures Market, 2006. 